\title{
Utilization of Primary Health Care and Its Associated Factors among Women of Childbearing Age Living in Mogadishu-Somalia
}

\author{
Abdirizak Yusuf Ahmed', Ahmed M. Husein² \\ ${ }^{1}$ Demartino Hospital, Mogadishu, Somalia \\ ${ }^{2}$ Faculty of Health Sciences, Department of Public Health, Capital University of Somalia, Mogadishu, Somalia \\ Email:drjalaal@hotmail.com, Hamuudiph15@gmail.com
}

How to cite this paper: Ahmed, A.Y. and Husein, A.M. (2020) Utilization of Primary Health Care and Its Associated Factors among Women of Childbearing Age Living in Mogadishu-Somalia. Health, 12, 1640-1652. https://doi.org/10.4236/health.2020.1212120

Received: October 10, 2020

Accepted: December 28, 2020

Published: December 31, 2020

Copyright ( 2020 by author(s) and Scientific Research Publishing Inc. This work is licensed under the Creative Commons Attribution International License (CC BY 4.0).

http://creativecommons.org/licenses/by/4.0/ (c) (i) Open Access

\section{Abstract}

Background: The Somali people have some of the worst health indicators in the world, with women and children most affected. Despite modest improvements in maternal and child mortality rates in the last five years, inequities amongst communities meant that some children and mothers are disproportionately exposed to otherwise avoidable and treatable diseases. The broad aim of this study is to assess utilization of Primary Health Care (PHC) and Its associated factors among Women of Childbearing age living In Mogadishu Somalia. Methodology: Descriptive and Analytical cross-sectional community-based study was conducted among Women of Childbearing age that were living in two districts (Hodan and Abdul-Aziz Districts)-Mogadishu-Somalia-From May 2019 to September 2019. A total of 395 of Women of Childbearing age were targeted during the study period. Descriptive and analytical statistics was used using Statistical package for social science (SPSS) version 20 statistical software. The data were showed tables, figures and graphs for describing the data. Results: The study found that Most of respondents were between 15 to 25 years $41.5 \%$ (395 sample sizes), while the age of group of $>45$ to 55 was only $6 \%$ (395 sample size). According to the district $76.5 \%$ of respondents were from Hodan, while 23.5\% (395 sample size) of respondents were from Abdul-Aziz district. According to awareness to the need of a pregnant mother to be vaccinated at the Mother and child health $(\mathrm{MCH})$ Most respondents $48.2 \%$ (395 Sample size) said that pregnant women may or may not need to be vaccinated. According to health-seeking decisions only $3 \%$ of ever married respondents were made by themselves whilst $97 \%$ of them were made by their husband. Age group was not significantly associated with the level of utilization of Primary Health Care (PHC); this is different from study in Kenya showing that age is an important factor in determining the use 
of skilled assistance, early antenatal care visits and more than four antenatal visits. Conclusion: The study concluded and recommended that the level of utilization of primary health care is poor and lower than other studies around Somalia as well as World Health Organization (WHO). recommendation And the study recommended that enhancing awareness importance of primary health care (PHC) utilization and empowering women Health care-seeking behavior and their husbands.

\section{Keywords}

Utilization, Awareness, PHC, Hodan, Abdul-Aziz

\section{Background}

Maternal mortality remains a public health challenge across many developing countries around the world. For instance, in 2013, about 289,000 women died to causes related to childbirth. Out of these deaths, about 179,000 were from developing countries [1].

In sub-Saharan Africa, women's lifetime risk of dying in childbirth stands at 1 in 38 relatives to 1 in 3700 from developed countries. In sub-Saharan Africa, Malawi reported the highest maternal mortality rated at 510 deaths per 100,000 live births which implied that 1 in every 34 women died during childbirth, in the same year [2].

Previous scholars asserted this public health challenge to preventable direct causes upon women's timely seeking of maternal health care services during and after gestation period [3] [4].

Health has been recognized as a fundamental human right, regardless of sex, political affiliation, social class or ethnicity, as well as the right to minimum condition of wellbeing, including the provision of medical care and public services for all people [5].

Improving health throughout the world is a gigantic task requiring global cooperation. The international health care system was first recognized at the first international scientific conference in 1851 [2] after which the World Health Organization (WHO) introduced a system of cooperation against the spread of diseases. A WHO conference held in Alma-Ata in 1978, proclaimed Primary Health Care (PHC), as a concept that calls for the overall promotion of health by supporting the individual, the family and the community, by defining the active participation of the community, their needs and ways to meet them [6].

The neglect of women's health needs was highlighted in 1985 when Rosenfield and Maine, in their article "Where is the $\mathrm{M}$ in $\mathrm{MCH}$ ? ", called for action against the silent but vast problem of women dying in pregnancy and childbirth (Rosenfield \& Maine 1985). They pointed out that maternal and child health (MCH) programs were addressing mainly the needs of the child and were overlooking the mother. In 1987 a Safe Motherhood Conference was held in Nairobi, Kenya, 
which was the starting point for the Safe Motherhood Initiative (SMI). Awareness campaigns and meetings were started in developing countries in order to mobilise governments and policy-makers to take action against the long neglected problem of women dying in pregnancy and childbirth. In order to assess the magnitude of the problem, maternal mortality studies were performed in many countries. It was realized that many deaths occurred in silence and were never reported [7].

Poor usage of skilled attendance and maternal primary health care services results in high levels of maternal mortality in the developing countries. The maternal mortality ratio in Nigeria, for example, is estimated at 560 per 100,000 women [1]. Various studies have been done around the world to identify factors that influence the choice of child-bearing women's health care. Some of the identified factors include cost of services [2] [3] [4] [5] [6]; sociodemographic and educational level of the client [7] [8] [9] [10]; women's level of autonomy in making health care decisions [2] [5]; physical accessibility to health care services and the type of health services rendered, disease pattern and healthcare workers attitude also another Studies within sub-Saharan Africa have attributed such variations in maternal health outcomes and any issues related to pregnancy and childbirth within the region to socioeconomic disparities [2] [3] [4] [7] [10] [11] [12] [13]. Maternal deaths could be prevented if women were able to access and utilize good quality services, especially when complications arise [14]. However, in reality, most women experience serious barriers to accessing services or even if they do reach them, the services themselves are often of insufficient quality or effectiveness. Also, in recent years, sector-wide strategies focused on skilled attendance have aimed to generate demand as well as augment supply. Kenya has a massively growing population but more than half of its population makes up the majority of poor people living under the poverty line do not have enough earnings for their basic needs, food, water and shelter. They are therefore the people who rely most on government subsidies for health care. Unfortunately, they face many barriers in accessing health care and usually end up receiving poorer services than the minority rich population [12]. Ethiopia suffers from a severe shortage of both health personnel and accessible facilities. Approximately 30 percent of households were estimated to live more than 10 kilometres from the nearest hospital, health center, or health station. Urban areas with 4 - 6 percent of the total population have 44 percent of all health facilities [13]. Ethiopia is a leading contribution to the maternal death figure in SSA because of its high maternal mortality ratio. In Ethiopia maternal mortality rate was estimated to be 673 deaths per 100,000 live births which are among the highest in the world (14). According to the Ethiopian demographic and health survey (EDHS), the antenatal care (ANC), postnatal care (PNC) and skilled delivery care in Somali region was $21.5 \%, 8.4 \%$ and $7.4 \%$ respectively [15] Public health facilities in Somalia is generally inadequate and the quality of services at the existing health units is generally unsatisfactory In addition, the private sector, of which the pharmacy 
often constitutes the prime location for consultation, play a major role in providing quality health care. However, due to financial constrains not all Somali populations use the facilities and people with the financial means mainly access the private facilities [14].

\section{General Objective}

The main purpose of this study was to assess Utilization of PHC and it's associated with Risk Factors among Women of Childbearing age In Mogadishu-Somalia.

The specific objectives of the study was:

1) To measure the utilisation of primary health care services among woman of childbearing age living in Mogadishu Somalia;

2) To assess the awareness towards primary health care among woman of childbearing age living in Mogadishu Somalia;

3) To determine the health facility factors contributing to the utilization of primary health care among women of childbearing age in Mogadishu Somalia;

4) To assess socio-demographic factors associating with utilization of primary health care among women of childbearing in Mogadishu Somalia.

\section{Methods \& Materials}

\subsection{Study Design}

Across-sectional study design was conducted to obtain reliable information about the utilization of primary health care service among women of childbearing age, in Mogadishu, Somalia.

\subsection{Study Population}

The populations of Mogadishu are estimated to be 1.5 million according to (PESS Population by district final 2017). The target population is all women of childbearing age living Mogadishu.

According the final population estimate by district 2017 Mogadishu is composed of 16 districts which will be divided in to two equal strata each containing eight districts and each strata one district was selected by simple random sampling technique.

\subsection{Study Area}

The study was conducted in Mogadishu, the capital of Somalia. It is a coastal city in east Africa. It is home to over a 2 million inhabitants. Quantitative data was obtained from women of childbearing age living in two randomly selected districts in Mogadishu Somalia

\subsection{Selection Criteria}

\subsubsection{Inclusion and Exclusion Criteria}

Any women in childbearing age and living in the selected districts and accepted to participate the study. 


\subsubsection{Exclusion and Exclusion Criteria}

Any women not in childbearing age and not living in the selected districts and refused to participate the study.

\subsection{Sampling Techniques}

After randomly selecting the districts two sub districts was randomly selected and then three main roads was randomly selected from each sub district, then every second house $(1,3,5)$ will be selected. If the target population was not found in the second selected house the next house was taken until sample size is obtained.

\subsection{Sample Size}

In the calculation of sample size sloven formula was used since the target population is known:

Through random sampling Hodan and Abda-aziz has been selected and the sample size was obtained from the women childbearing age living in the two districts.

Hodan 24,897 + Abda-aziz 7704 and total target population is 32,601

$$
n=N \backslash 1+N * e^{2} \quad \text { Where: } \mathrm{n}=\text { is sample size. }
$$

$N=$ is total population, which is the estimated women childbearing age living in the two districts and they 32,601 .

$e=$ is desired error margin which is 0.05 .

Therefore by simply applying the above values to the formula we got the following sample size: $n=395$.

\subsection{Data Collection}

\section{Data collection methods:}

The data collected from structured questionnaire used in this study was developed and consisted of 4 sections which were used a well-designed questionnaire of the patients, the questionnaire comprises of 4 sections as follows.

Section 1: General characteristics of respondent in this part, there were 8 items asking general characteristics of respondent including, age of respondent, District from the respondents, Marital status, if not single, age of $1^{\text {st }}$ marriage, income per month level,, living condition, Employment status and Level of education.

Section 2: include Awareness of the mothers towards $\mathrm{MCH}$, knowledge about the maternal health services provided, family planning and so on.

Section 3: includes health facility factors which according to (Distance to health facility, Transportation method, Waiting time for health works, Service availability at needed time and Level of satisfaction).

Section 4: Primary health care utilization including (ANC visits, Timing of visit, and Vaccination status, Family planning and child spacing etc.).

\subsection{Data Analysis}

The raw data entered to the SPSS program of statistics version 20 , in order to 
analyses data. After data entry, the data processed and the required information obtained through the SPSS program. A comparison between the groups made using the Pearson chi square, a descriptive statistics, association between dependent and independent variables analyzed by calculating the Odd ratios and 95\% confidence level. The processed information presented through Tables 1-3 and charts.

\subsection{Ethical Considerations}

Medical research involving human subjects raises ethical concerns about the subject's right to privacy; all study subjects will be asked to give informed consent and assured regarding confidentiality and anonymity of data. In order to make sure that the study is ethically kept, the researchers fulfilled the following issues.

\subsubsection{Institutional Consent}

Ethical approval for the study obtained from the researchers and ethics committee of Ministry of Health.

\subsubsection{Informed Consent}

To get signed letter of informed consent of the respondent, the researcher assistance introduced themselves to the participants and the study explained to the participants on the procedure. The purpose of the study explained to the respondents, they also informed about the criteria of being selected to participate in the study, procedures to follow and any risks and benefits which may be involve during the study. They also being informed about the duration of the study, and they assured that confidentiality was ensured.

\section{Results}

This chapter covers the analysis and interpretation of finding about the utilization of primary health care and its associated factors among women of childbearing age in Mogadishu, Somalia. Data of the questionnaire were analyzed using SPSS version 20. The obtained results have been sorted out into four main heading: Socio-Demographic Information, Awareness towards Primary Health Care, Health Factors and Level of Utilization Primary Health Care Service.

\subsection{Univariate Analysis; Socio-Demographic Information}

Eight questions were related to the demographic information mainly about variables such as Age of Respondent, Marital Status, Level of Education, Living Condition, District, Employment Status, as well as Daily Income.

According to age distribution, Most of respondents were between 15 to 25 years $(41.5 \%)$ while the age of group of $>45$ to 55 were only (6\%). According to the district $76.5 \%$ of respondents were from Hodan, while $23.5 \%$ of respondents were from Abda-aziz district. 
Table 1. Describes the demographic characteristics of the respondents.

\begin{tabular}{|c|c|c|c|}
\hline Variables & & Frequency & Percentage \\
\hline \multirow{5}{*}{ Age } & 15 to 25 years & 164 & $41.5 \%$ \\
\hline & $>25$ to 35 years & 111 & $28.2 \%$ \\
\hline & $>35$ to 45 years & 96 & $24.3 \%$ \\
\hline & $>45$ to 55 years & 24 & $6.0 \%$ \\
\hline & Total & 395 & $100 \%$ \\
\hline \multirow{3}{*}{ District } & Hodan & 302 & $23.5 \%$ \\
\hline & Abda-aziz & 93 & $76.5 \%$ \\
\hline & Total & 395 & $100 \%$ \\
\hline \multirow{5}{*}{ Marital Status } & Single & 96 & $24.2 \%$ \\
\hline & Married & 149 & $37.8 \%$ \\
\hline & Divorced & 112 & $28.3 \%$ \\
\hline & Widowed & 38 & $9.7 \%$ \\
\hline & Total & 395 & $100 \%$ \\
\hline \multirow{4}{*}{$\begin{array}{c}\text { if not single, age of } 1^{\text {st }} \\
\text { marriage }\end{array}$} & $<18$ years & 121 & $40.5 \%$ \\
\hline & 18 to 25 years & 139 & $46.5 \%$ \\
\hline & $>25$ years & 39 & $13 \%$ \\
\hline & Total & 299 & $100 \%$ \\
\hline \multirow{4}{*}{ Average daily income } & $<3 \$$ & 113 & $28.7 \%$ \\
\hline & 3 to $6 \$$ & 201 & $50.8 \%$ \\
\hline & $>6 \$$ & 81 & $20.5 \%$ \\
\hline & Total & 395 & $100 \%$ \\
\hline \multirow{3}{*}{ Employment status } & Employed & 33 & $8.3 \%$ \\
\hline & Unemployed & 362 & $91.7 \%$ \\
\hline & Total & 395 & $100 \%$ \\
\hline \multirow{3}{*}{ Living condition } & IDP & 352 & $89 \%$ \\
\hline & Non IDP & 43 & $11 \%$ \\
\hline & Total & 395 & $100 \%$ \\
\hline \multirow{3}{*}{$\begin{array}{l}\text { Health seeking } \\
\text { Decisions if ever } \\
\text { married }\end{array}$} & My husband & 290 & $97 \%$ \\
\hline & My self & 9 & $3 \%$ \\
\hline & Total & 299 & $100 \%$ \\
\hline \multirow{5}{*}{ Level of education } & Illiterate & 188 & $47.5 \%$ \\
\hline & Primary Education & 86 & $21.8 \%$ \\
\hline & Secondary Education & 85 & $21.5 \%$ \\
\hline & University level & 36 & $9.2 \%$ \\
\hline & Total & 395 & $100 \%$ \\
\hline
\end{tabular}


Table 2. Details the health facility factors.

\begin{tabular}{|c|c|c|c|}
\hline Variables & & Frequency & Percentage \\
\hline \multirow{3}{*}{ Distance to health facility } & $<2.5 \mathrm{~km}$ & 213 & $53.9 \%$ \\
\hline & $>2.5 \mathrm{~km}$ & 182 & $46.1 \%$ \\
\hline & Total & 395 & $100 \%$ \\
\hline \multirow{4}{*}{ Transportation method } & Bus & 107 & $27.1 \%$ \\
\hline & Walking & 219 & $55.4 \%$ \\
\hline & Bajaj & 69 & $17.5 \%$ \\
\hline & Total & 395 & $100 \%$ \\
\hline \multirow{4}{*}{$\begin{array}{l}\text { Waiting time for health } \\
\text { works }\end{array}$} & $<15$ minuets & 54 & $13.6 \%$ \\
\hline & 15 to 30 minuets & 187 & $47.4 \%$ \\
\hline & $>30$ minuets & 154 & $39 \%$ \\
\hline & Total & 395 & $100 \%$ \\
\hline \multirow{3}{*}{$\begin{array}{l}\text { Service availability at } \\
\text { needed time }\end{array}$} & Not available & 236 & $59.7 \%$ \\
\hline & Available & 159 & $40.3 \%$ \\
\hline & Total & 395 & $100 \%$ \\
\hline \multirow{4}{*}{ Attitude of health workers } & Good & 172 & $43.5 \%$ \\
\hline & Average & 139 & $35.2 \%$ \\
\hline & Poor & 84 & $21.3 \%$ \\
\hline & Total & 395 & $100 \%$ \\
\hline \multirow{3}{*}{ Level of satisfaction } & Good & 229 & $58 \%$ \\
\hline & Poor & 166 & $42 \%$ \\
\hline & Total & 395 & $100 \%$ \\
\hline
\end{tabular}

Table 3. Describes the utilization of primary health care.

\begin{tabular}{cccc}
\hline Variables & Frequency & Percentage \\
\hline \multirow{2}{*}{ ANC visits } & Never visited & 118 & $39.5 \%$ \\
& $1^{\text {st }}$ trimester & 139 & $46.5 \%$ \\
& $2^{\text {nd }}$ and $3^{\text {rd }}$ trimester & 42 & $14 \%$ \\
Total & 299 & $100 \%$ \\
\hline Delivery & At health centre & 84 & $42 \%$ \\
& Home $/$ TBA & 116 & $58 \%$ \\
& Total & 200 & $100 \%$ \\
\hline TT Vaccination status & Never been vacated & 214 & $54.2 \%$ \\
& 1 to 3 & 94 & $23.8 \%$ \\
& $>3$ & 87 & $22 \%$ \\
\hline
\end{tabular}




\begin{tabular}{lccc} 
Continued & & & \\
\hline & None, or only breast feeding & 173 & $56.5 \%$ \\
Family planning and child & Condom & 5 & $2.3 \%$ \\
spacing & Implant & 24 & $8.6 \%$ \\
& Injection contraceptive & 47 & $14.4 \%$ \\
& Oral contraceptive pills & 72 & $18.2 \%$ \\
& Total & 299 & $100 \%$ \\
\hline \multirow{2}{*}{$\begin{array}{c}\text { feeding program for pregnant } \\
\text { and lactating women }\end{array}$} & Never & 91 & $32.6 \%$ \\
& Once & 119 & 42.7 \\
& More than once & 69 & $24.7 \%$ \\
\hline & Total & 279 & $100 \%$ \\
\hline
\end{tabular}

According to the living status $89.0 \%$ were Non-IDP campus while $11.0 \%$, were IDP camps.

According to the marital status $37.8 \%$ were married, while only $9.7 \%$ were widowed. Regarding to the level of education $47.5 \%$ of respondents were illiterate, $9.2 \%$ were university. According to the employment $8.3 \%$ were employed, and $91.7 \%$ were unemployed.

According to the average daily income most of $50.8 \%$ of respondents were between $3 \$$ to $6 \$$, while $20.5 \%$ were $>6 \$$. Regarding Age of the $1^{\text {st }}$ marriage $40.5 \%$ were $<18$ years old, while only $13 \%$ were $>25$ years.

Speaking of health seeking decisions only $3 \%$ of ever married respondents were made by themselves whilst $97 \%$ of them were made by their husband.

Figure 1 shows awareness to primary health care.

Awareness of the participants assessed by the following questions, participants who get the correct answer of $60 \%$ of the question considered as having a good awareness, however those get less than that categorized as poor awareness.

\subsection{Health Facility Factors}

Speaking of distance to the health facility $53.9 \%$ are less than $2.5 \mathrm{~km}$ away from health facility.

Most of respondents $55.4 \%$ come to the health facility by walking, while only $17.5 \%$ come by Bajaj Regarding the waiting time $47.4 \%$ wait 15 to 30 minutes.

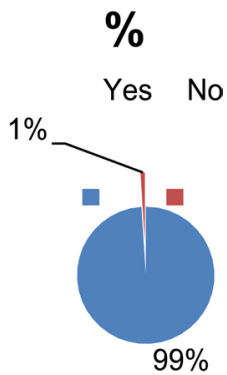

Figure 1. Describes how many respondents heard of mother and child health center. 
According to the attitude of health workers most of respondents $43.5 \%$ categorized them as having good attitudes. Regarding level of satisfaction, $42 \%$ of participants were poorly satisfied to the health facility.

\subsection{Utilization of Primary Health Care}

The utilization of primary health care among women of childbearing age were assessed by their level of using the common primary health care services such as ANC, Vaccination, Delivery, Family Planning, Feeding of Pregnant and Lactating Women.

According to the timing of visits most of respondents among those visiting the ANC (181) only $22.1 \%$ of them had visited in their $1^{\text {st }}$ trimester while $77.9 \%$ visited in their $2^{\text {nd }}$ and $3^{\text {rd }}$ trimesters.

Regarding Delivery $42 \%$ of respondents was delivering in health facility whilst $58 \%$ of them were delivered by TBA.

Speaking of TT vaccination most of participants $54.2 \%$ have never been vaccinated while only $22 \%$ of them have been vaccinated more than 3 .

According to family planning and child spacing most of participant have none or only used breastfeeding as family planning method, while the most common used method was oral contraceptive $18 \%$.

Regarding the pregnant and lactating women feeding program, $32.6 \%$ of respondents have never benefited from the feeding program while only $24.7 \%$ of them used more than once.

Figure 2 shows the level of utilization.

The level of utilization among participants depends on their utilization of each primary health program, the level has been categorized into three categories which, proper utilization, Average utilization and not utilizing.

Participants that utilize more than $80 \%$ of primary health care are considered as good utilization category, while those with $50 \%$ to $79 \%$ are categorized as average utilization and those having less than $50 \%$ are considered as poor utilization.

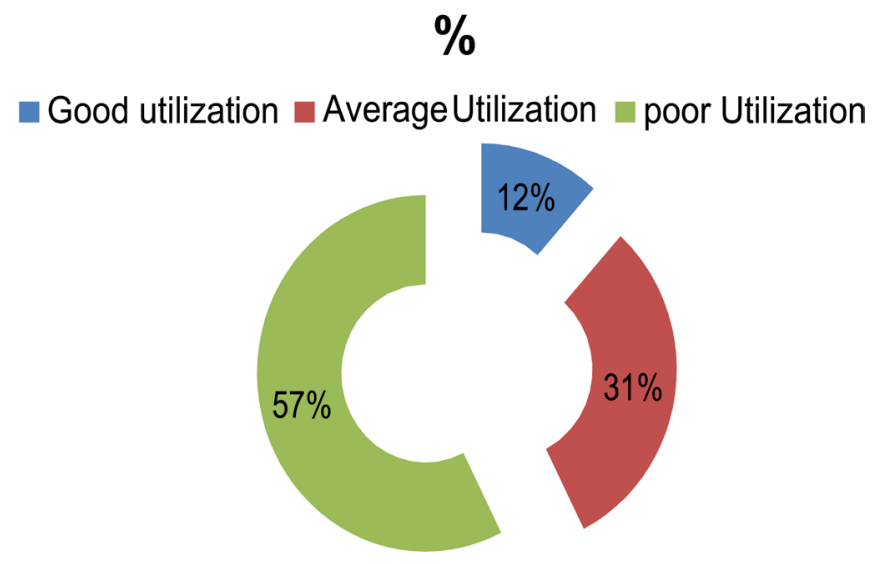

Figure 2. Describes the level of utilization of primary health care among respondents. 


\section{Discussions}

The utilization of primary health care documented in this study is $57 \%$ poor utilization while $31.1 \%$ is average and only $11.9 \%$ is good.

ANC visits among the participants of this study demonstrated that only $14 \%$ of them had on their $1^{\text {st }}$ trimester. This result is also higher compared to 2011 EDHS reported where only $11 \%$ of women in Ethiopia made their first antenatal care visit before the fourth month of pregnancy [8].

Many factors are related to the utilization antenatal care, including the health seeking decisions, in which this study showed that participants that make the health seeking decision by them are $85.7 \%$ of those who attend antenatal care in their $1^{\text {st }}$ trimester.

Maternal education is strong factor in determining health service utilization, with $61.7 \%$ of those with good utilization of primary health care service are at university level.

Many factors are related to the utilization antenatal care, including the health seeking decisions, in which this study showed that participants that make the health seeking decision by themselves are $85.7 \%$ of those who attend antenatal care in their 1st trimester This result is relevant with study in Nigeria Women whose husband approves of antenatal care were more likely to have used prenatal care than women whose husband did not approve of ANC [9] Maternal education is strong factor in determining health service utilization, with $61.7 \%$ of those with good utilization of primary health care service are at university level. This is consistency with the findings from elsewhere in the World (Letamo, 2003; Stephenson, 2006; Navaneetham, 2002). There are a number of explanations for why education is a key determinant of health service use. Education is likely to enhance female autonomy so that women develop greater confidence and capability to make decisions about their own health [10].

\section{Conclusions}

This study demonstrates the level of utilization of primary health care among women of childbearing age as well as factors that are determining the level of utilization

The level of utilization of primary health care is poor and lower than other studies around Somalia as well as WHO recommendation.

Factors such usage of $1^{\text {st }}$ marriage, level of education, level of awareness, service availability at needed time and employment status are significantly associated with level of utilization.

Age of respondents, average daily income, marital status and distance to health facility were significantly associated with the utilization of primary health care in this study.

\section{Recommendations}

The awareness of Women of childbearing is important factors in utilization pri- 
mary health care as shown in this study, awareness campaigns with pre-structured and well designed as well as in coordination with ministry of health and local authorities through well-trained community health workers with target structured message and boosters as well use of media.

Service availability at needed time is also a significant factor; since women are always busy with their child and home needs in the morning which the working time for most of health facility, its recommended that working hours for providing primary health should redesign and service availability at any needed time should be strengthened through coordination of health workers and monitoring by the ministry of health

Awareness of husband regarding the right of women for healthy b pregnancy care as well as safe giving birth is crucial factor in achieving safe motherhood.

Further researches in other contributors such the knowledge and attitude of women in childbearing age.

\section{Conflicts of Interest}

The authors declare no conflicts of interest regarding the publication of this paper.

\section{References}

[1] WHO, UNICEF, UNFPA and The World Bank (2014) Trends in Maternal Mortality in: 1990 to 2013. WHO UNICEF, UNFPA and The World Bank, Geneva.

https://www.who.int/reproductivehealth/publications/monitoring/maternal mortality-2013/en/.

[2] United Nations (2008) United Nations: Millenium Development Goals Report. United Nations, New York.

[3] Geubbels, E. (2006) Epidemiology of Maternal Mortality in Malawi. Malawi Medical Journal, 18, 206-225.

https://www.ncbi.nlm.nih.gov/pmc/articles/PMC3345624/pdf/MMJ1804-0206.pdf https://doi.org/10.4314/mmj.v18i4.10923

[4] Leigh, B., Mwale, T.G., Lazaro, D., Lunguzi, J. (2008) Emergency Obstetric Care: How Do We Stand in Malawi? International Journal of Gynecology \& Obstetrics, 101, 107-111. https://pubmed.ncbi.nlm.nih.gov/18291400/

[5] The Universal Declaration of Human Right (2014) 60th Anniversary Special Edition 1948-2008. https://www.ohchr.org/EN/UDHR/Documents/60UDHR/bookleten.pdf

[6] Ogbole, J.O. (1981) Environmental Sanitation in Plateau State. A Political Economy of Health Science, Department of Political Science, A.B.U. Zaria. http://www.ijoart.org/docs/AN-ASSESSMENT-OF-THE-PRIMARY-HEALTH-CA RE-SERVICES-AND-UTILIZATION.pdf

[7] Campbell, O. and Graham, W. (1991) Measuring Maternal Mortality and Morbidity: Levels and Trends. Maternal and Child Epidemiology Unit Publication, London School of Hygiene and Tropical Medicine, London. https://www.ncbi.nlm.nih.gov/books/NBK361907/pdf/Bookshelf_NBK361907.pdf

[8] Republic of Somaliland Ministry of Health and Labour, KEMRI Welcome Trust Collaborative Programme, UNICEF Somalia and WHO Somalia (2008) Fever Treat- 
ment Seeking Behavior in Republic of Somaliland: Results of Two Cross-Sectional Surveys in Three Rural Communities.

https://somalia.savethechildren.net/sites/somalia.savethechildren.net/files/library/H ealth\%20system\%20in\%20Somalia_CHASP\%20research\%20baseline\%20report_201 8_1.pdf

[9] Sumera, A.A., et al. (2018) Factors Affecting the Utilization of Antenatal Care among Pregnant Women: A Literature Review.

https://www.alliedacademies.org/articles/factors-affecting-the-utilization-of-antenat al-care-among-pregnant-women-a-literature-review-10793.html https://doi.org/10.35841/neonatal-medicine.2.2.41-45

[10] Dev, R.A., et al. (2010) Women's Autonomy in Household Decision-Making: A Demographic Study in Nepal.

https://reproductive-health-journal.biomedcentral.com/articles/10.1186/1742-4755$\underline{7-15}$ https://doi.org/10.1186/1742-4755-7-15

[11] Graham, W.J., Bell, J.S., and Bullough, C.H. (2001) Can Skilled Attendance at Delivery Reduce Maternal Mortality in Developing Countries? Studies in Health Services Organisation and Policy, 17, 97-130. http://jsieurope.org/safem/collect/safem/pdf/s2934e/s2934e.pdf

[12] Goli, S., Doshi, R., and Perianayagam, A. (2013) Pathways of Economic Inequalities in Maternal and Child Health in Urban India: A Decomposition Analysis. PLoS ONE, 8, e58573.

https://journals.plos.org/plosone/article?id=10.1371/journal.pone.0058573 https://doi.org/10.1371/journal.pone.0058573

[13] Overbosch, G., Nosowah-nuamah, J. and Kanden, B.D. (2002) Determinants of Antennal Care We Ghana Center for World Food Studies, Staff Working Paper Workshop. https://pdfs.semanticscholar.org/f354/261a1ca4ab87553751a00f38778c6eefe1b9.pdf

[14] WHO (2005) Maternal Mortality in 2005: Estimates Developed by WHO, UNICEF, UNFPA and The World Bank, Geneva. https://www.who.int/whosis/mme_2005.pdf

[15] Central Statistical Authority (CSA) and ORC Macro Ethiopian Demographic and Health Survey (2011) Addis Ababa Ethiopia and Calverton, Maryland, USA: CSA and ORC Macro. https://dhsprogram.com/pubs/pdf/fr255/fr255.pdf 